\title{
El sistema sanitario vigente y el ideario de mayo 68
}

\author{
J. Cabanes
}

\section{Resumen}

Se cumplen ahora cuarenta años de la última revolución libertaria en Europa. En el recuerdo queda la acción directa en las calles y la ocupación de fábricas, pero hubo también una ideología revolucionaria poco conocida por su falta de estructuración y por la rapidez con la que se disolvió la revuelta.

En este artículo se revisan algunos aspectos de su crítica a la organización sanitaria a la que consideran un factor más del sometimiento del asalariado, y un soporte de la clase dominante. A través de sus elementos más característicos, el paradigma organicista, el papel del hospital y la ideología médica se consolida el orden social.

PALABRAS CLAVE: Mayo 68, Medicina y sociedad. Capitalismo y medicina

The current health system and the spirit of may 68

\section{Summary}

Forty years after the '68 May revolt, we have thought of interest to retrieve part of the revolutionary ideology concerning the rol of medical practice in the society they would to change.

In essence they said: the current organization of health care, although masked by mysticism, provides political support to the dominant class and favours socio-economic exploitation. Relevant features of medical structures, the hospital, the traditional medical mentality, the biologistic paradigm, etc. reinforce the hierarchical order in the capitalist society.

Se cumplen ahora cuarenta años de la última y efímera revolución libertaria de Europa, la revolución de los famosos slogans: "prohibido prohibir" o "debajo del asfalto está la playa". Por eso me parece una ocasión oportuna para

Recibido: 15-10-08. Aceptado: 12-11-08 volver sobre ciertos aspectos poco conocidos o simplemente ignorados.

La revolución fue participada por todos los grupos sociales y naturalmente por el estamento sanitario. No se limitó a la algarada callejera y la ocupación de edificios públicos sino que, conscientes de que sin una base ideológica la rebelión se diluiría en sí misma, los participantes crearon unos "Comités de Acción" en donde se debatieron las ideas con las que y contra las que luchar en cada faceta de la sociedad. Las ideas referentes a la sanidad nos han sido transmitidas por un pequeño libro publicado por François Maspero titulado "Médecine et Hôpital = silence et répression" y traducido al castellano con el título: "Contra la Medicina liberal"'. En síntesis, denuncia que la estructura sanitaria es un subsistema de la estructura socioeconómica general (por supuesto, capitalista): una clase que obtiene grandes plusvalías forzando a consumir lo que produce, a una masa complacida por los bienes que consigue, ignorante y por tanto fácilmente alienada, y dispuesta a asumir su culpabilidad en las crisis sociales, por lo que es sencillo repercutir en ella las consecuencias económicas de la crisis. La organización y el ejercicio de la Medicina ayudan a la consolidación de la clase en el poder y son un elemento de adoctrinamiento como lo es la enseñanza o la estructura jurídica.

Aunque una serie de tópicos tradicionales, la imagen del médico como un ser dedicado a sus semejantes, sus desvelos y sacrificios, su permanente disponibilidad, etc. mitifican la actuación médica, sus objetivos son: a) mantener a la población en situación de trabajar; b) producir consumo y c) mantener a la población en situación de consumir provocando además el consumo de Medicina. El análisis de diferentes aspectos de la organización sanitaria pone al descubierto estas hipótesis:

El paradigma médico en el que se apoya. La enfermedad es la interacción de la biología con la presión social. Se traiciona su sentido si se la objetiva como disfunción de un órgano. La Medicina exige la relación entre dos individuos. Se pervierte esta relación disociando al enfermo en cuerpoespíritu y considerando sólo su parte corporal. Si el médico tratase al hombre total estaría obligado a tener en cuenta 
la situación socio-familiar y laboral del enfermo, que a la postre es lo que genera la enfermedad. Aceptando este paradigma biologista u organicista, el médico sólo se ocupa de neutralizar la enfermedad eliminando o atenuando las manifestaciones de lo que él considera un órgano enfermo.

El Hospital es una parte fundamental de la organización sanitaria, donde se presta la atención altamente especializada y donde acude confiado el enfermo respaldado por la garantía científica. Tiene por misión tratar, enseñar e investigar. Pero a cada una de estas opciones se opone otra de un significado completamente diferente: funcionamiento, poder, placer.

El hospital ha supuesto un gasto que hay que hacer rentable, y para ello se procura optimizar sus prestaciones vigilando rigurosamente las estancias, ingresos, utilización de recursos, etc. Paulatinamente, esta vigilancia se vuelve obsesiva de forma que el funcionamiento del hospital se convierte en un fin en sí mismo y el hospital perfecto recoge muy poco de los resultados sobre el enfermo y mucho de la eficiencia de la institución. El enfermo no es el beneficiario del funcionamiento sino su instrumento. Para llevar a cabo esta dinámica se utiliza como intermediario al médico compensándole con:

Poder, sobre sus colaboradores y subordinados, sobre los servicios auxiliares y sobre todo sobre el enfermo.

Placer, diagnóstico y terapéutico. Poniendo en su mano métodos de diagnóstico de alta tecnología que le permiten observar el cuerpo humano como nunca antes había podido hacer, y sofisticadas medicaciones con las que abordar tratamientos experimentales sobre patologías de difícil curación. El enfermo es el banco de pruebas.

Con todo ello, el hospital se convierte en una empresa capitalista de Estado que genera plusvalías, explota a una clase trabajadora fragmentada y utiliza a los médicos.

El médico es el agente involuntario y la mayoría de las veces inconsciente de esta manipulación que, sin embargo, se ve facilitada por algunos aspectos de la ideología médica tradicional:

a) La jerarquía está en la base de su funcionamiento. Justificada por la conveniencia de rapidez en la toma de decisiones, a menudo es un reparto arbitrario de funciones que anula la capacidad de los subordinados aunque les permite eludir su responsabilidad directa amparándose en quien ejerce esta jerarquía, en muchas ocasiones una persona no capacitada para ello. Se tolera sin oposición por tradición, por miedo o por el convencimiento de que, a su debido tiempo, a todos llegará el momento de poder ejercerla.

b) A partir de la Edad Media, a medida que la Iglesia va perdiendo prestigio social, el médico asume el papel de consejero, tutor y protector de su prójimo y, en la medida que toma ascendiente sobre él se da cuenta de que ha adquirido poder político e incluso acaba convirtiéndose en el dictador de las normas morales de la sociedad con sus consejos de higiene y salud.

c) Al convertir el saber médico en una Botánica clínica, conjunto de síntomas y signos que identifican el padecimiento del enfermo, se facilita la aparición de especialidades cada vez más diferenciadas unas de otras y cada vez más alejadas de la realidad del paciente.

d) Considerando la muerte como expresión de su fracaso se plantea la necesidad de ocultarla. Eliminando toda la transcendencia que para el enfermo puede tener el desenlace definitivo, la combate con el encarnizamiento clínico para tener la evidencia de que se ha luchado hasta la última posibilidad o con el olvido del paciente crónico incurable.

Es así como el hombre enfermo sigue padeciendo el sometimiento a la clase dominante al forzarlo a sentirse:

Discapacitado con respecto a los otros miembros de la sociedad porque no produce $y$, por tanto, no cumple los fines sociales.

Culpable porque su enfermedad proviene de su incumplimiento de las normas higiénicas.

Absolutamente dependiente de quien ostenta el saber médico en exclusiva por lo que no le es permitido opinar y, mucho menos, protestar.

Sin valor cuando se cronifica, ya que deja de interesar una situación que no tiene modificación médica posible y sólo recobra el interés en la sala de autopsias.

No es la intención de este trabajo establecer una valoración crítica sobre estas ideas sino simplemente traerlas a la actualidad, y la valoración quedaría a voluntad de los lectores. No obstante voy a dejar constancia de mi toma de postura: como súbdito de la medicina científica y de la civilización occidental me escandalizo de sus exageradas interpretaciones. Como intelectual, reconozco que en muchos aspectos tenían razón.

La revolución se saldó con pequeñas reformas: modificaciones en los exámenes de acceso al Internado, en la obtención del título de Doctor, incrementos salariales, etc. que es lo que se pactó finalmente con las autoridades sanitarias.

\section{Bibliografía}

1. Maspero, F.: "Contra la Medicina liberal". Barcelona. Editorial Estela. 1970.

Cabanes, J.: El sistema sanitario vigente y el ideario de mayo 68. Neurocirugía 2009; 20: 298-299.

Correspondencia postal: Jerónimo Cabanes. C. Pérez Pujol, 6. 46002 Valencia. 